\title{
Comparative Organization and Gene Expression Profiles of the Porcine Pseudoautosomal Region
}

\author{
P.J.Das D.K. Mishra S. Ghosh F. Avila G.A. Johnson B.P. Chowdhary \\ T. Raudsepp \\ Department of Veterinary Integrative Biosciences, College of Veterinary Medicine and Biomedical Sciences, \\ Texas A\&M University, College Station, Tex., USA
}

\section{Key Words}

Comparative organization - Embryonic development .

$\mathrm{FISH} \cdot$ Gene expression · Pig · Pseudoautosomal boundary .

Pseudoautosomal region · Sequence map

\begin{abstract}
The pseudoautosomal region (PAR) has important biological functions in spermatogenesis, male fertility and early development. Even though pig (Sus scrofa, SSC) is an agriculturally and biomedically important species, and its genome is sequenced, current knowledge about the porcine PAR is sparse. Here we defined the PAR in SSCXp/Yp by demarcating the sequence of the pseudoautosomal boundary at $X: 6,743,567$ bp in intron 3-4 of SHROOM2 and showed that SHROOM2 is truncated in SSCY. Cytogenetic mapping of 20 BAC clones containing 15 PAR and X-specific genes revealed that the pig PAR is largely collinear with other mammalian PARs or Xp terminal regions. The results improved the current SSCX sequence assembly and facilitated distinction between the PAR and X-specific genes to study their expression in adult and embryonic tissues. A pilot analysis showed that the PAR genes are expressed at higher levels than X-specific genes during early development, whereas the expression of PAR genes was higher at day 60 compared to day 26 , and
\end{abstract}

higher in embryonic tissues compared to placenta. The findings advance the knowledge about the comparative organization of the PAR in mammals and suggest that the region might have important functions in early development in pigs.

Copyright $\odot 2013$ S. Karger AG, Basel

The mammalian pseudoautosomal region (PAR) is a region of true sequence homology between the $\mathrm{X}$ and the Y chromosome [Galtier, 2004; Blaschke and Rappold, 2006; Raudsepp et al., 2012]. Sequences in the PAR are diploid, undergo recombination in males and females, and are not subject to dosage compensation by $\mathrm{X}$ inactivation in females [Ellis and Goodfellow, 1989; Brown and Greally, 2003]. The physical domain of the PAR lies between the terminal ends of the sex chromosomes and the pseudoautosomal boundary (PAB) - a border across which sequence homology between the sex chromosomes reduces and recombination stops [Blaschke and Rappold, 2006; Flaquer et al., 2008].

The PAR is necessary for sex chromosome pairing, recombination and proper segregation in male meiosis [Ellis and Goodfellow, 1989; Blaschke and Rappold, 2006; Mangs and Morris, 2007; Flaquer et al., 2008] and is

\section{KARGER}

(C) 2013 S. Karger AG, Basel

1424-8581/13/1411-0026\$38.00/0

E-Mail karger@karger.com

www.karger.com/cgr
Terje Raudsepp

Department of Veterinary Integrative Biosciences

College of Veterinary Medicine and Biomedical Sciences, Texas A\&M University College Station, TX 77843-4458 (USA)

E-Mail TRaudsepp@cvm.tamu.edu 
therefore critical for spermatogenesis, male fertility and the formation of a normal zygote. Additionally, the gene content of the PAR might also have an important role during development as evidenced by modeling abnormal early development using aneuploid embryonic [Urbach and Benvenisty, 2009] and induced pluripotent stem cells [Li et al., 2012] and by comparing the incidence of viable $\mathrm{XO}$ individuals across species with different PARs [Raudsepp et al., 2012]. Furthermore, because the PAR is a recombination hotspot [Filatov, 2004; Flaquer et al., 2008, 2009] and an elevated recombination rate has been associated with DNA methylation, it is possible that some PAR genes might be subject to genomic imprinting [Luedi et al., 2007; Sigurdsson et al., 2009].

Despite the important biological properties of the PAR and the availability of draft sequence assembly for the $\mathrm{X}$ chromosome in most domestic and many wild mammals (Ensembl, http://www.ensembl.org/index.html; UCSC, http://genome.ucsc.edu/), the current knowledge about the organization of the eutherian PAR is limited. The region is sequenced or relatively well-studied only in humans/primates [Skaletsky et al., 2003; Ross et al., 2005; Hughes et al., 2010, 2012] and mice [Ellison et al., 1996; Perry et al., 2001; Alföldi, 2008]. In other species, a variable degree of information for the PAR is available [reviewed by Raudsepp et al., 2012]: the approximate physical domain and gene content of the region is known for most domestic species and predicted for the porpoise [Van Laere et al., 2008] and armadillos [Sciurano et al., 2012]. However, the exact sequence of the PAB has so far been determined only in cattle/bovids [Van Laere et al., 2008]. Collectively, the data indicate that the PAR varies in size and gene content between species, suggesting that orthologous X-linked genes might be pseudoautosomal in one, and non-pseudoautosomal in another species.

Even though pig (Sus scrofa, SSC) is considered one of the most important agricultural species, as well as an important biomedical model for humans [Kuzmuk and Schook, 2011; Swine Genome Sequencing Consortium, 2012], current knowledge of the porcine PAR lags behind those of other domestic animals. While the recently published porcine genome sequence assembly [Swine Genome Sequencing Consortium, 2012] includes sequence information for $144 \mathrm{Mb}$ of the pig X chromosome, the $\mathrm{PAB}$ is not defined, thus precluding distinction between the PAR and X-specific sequences. So far, the confirmed PAR loci in pigs include cytogenetically mapped genes KAL1, PRKX and STS [Quilter et al., 2002], a marker pCMS14 [Ellegren et al., 1994] and a paternally imprinted QTL for loin weight [Duthie et al., 2009].

The Pig Pseudoautosomal Region and Its Boundary
In this study we generate an ordered physical map of the porcine PAR and precisely demarcate the region by delineating the PAB sequence. Additionally, we carry out a pilot study comparing the expression of selected PAR and $\mathrm{X}$-specific genes in adult and embryonic porcine tissues.

\section{Materials and Methods}

Selection of Genes to Demarcate the Pig PAR and PAB

Putative pig PAR genes were selected using the following sources: (i) the sequence assembly of the pig X chromosome (Sscrofa10.2; Ensembl, http://www.ensembl.org/index.html), (ii) tentative location of the PAB in pigs [Raudsepp et al., 2012], and (iii) the gene content of human [Ross et al., 2005], horse [Raudsepp and Chowdhary, 2008b], cattle [Das et al., 2009] and dog [Young et al., 2008] PARs for comparative information. As a result, 13 pig genes were selected to tag the terminal, middle and distal regions of the putative porcine PAR, as well as the adjacent X-specific region (table 1).

\section{Primer Design and Optimization}

Overgo and PCR primers for the putative PAR genes (online suppl. table 1; for all online supplementary material, see www. karger.com/doi/10.1159/000351310) were designed from the sequences of the pig genome assembly Sscrofa10.2 and from Roche 454 sequences of a flow-sorted SSCY (our unpublished data; flowsorted Y was kindly provided by M.A. Ferguson-Smith). PCR primers were also designed for $20 \mathrm{BAC}$ end sequences (BES) (online suppl. table 2; see below). Overgo primers were designed manually using NCBI guidelines (http://www.ncbi.nlm.nih.gov/projects/genome/probe/doc/TechOvergo.shtml), and Primer3 software [Rozen and Skaletsky, 2000] was used for constructing the PCR primers. The latter were optimized on male and female pig genomic DNA.

\section{Pig CHORI-247 BAC Library Screening and BAC DNA}

\section{Isolation}

Overgo primers were radioactively labeled and hybridized to male pig (ID\#Duroc 243-2) genomic BAC library CHORI-247 (http://bacpac.chori.org/library.php?id=473) high-density filters as described elsewhere [Gustafson et al., 2003; Avila et al., 2012]. Positive BAC clones were identified and picked from the library. The BAC clones corresponding to individual genes were identified by PCR using gene-specific primers (online suppl. table 1) and $\mathrm{BAC}$ cell lysates as a template. Isolation of DNA from individual BACs was carried out with the Plasmid Midi Kit (Qiagen) according to the manufacturer's protocol. The quality and quantity of BAC DNA were evaluated by gel electrophoresis and Nanodrop spectrophotometry.

\section{Chromosome Preparations and Fluorescence in situ}

Hybridization

Fluorescence in situ hybridization (FISH) was used to determine whether the genes belonged to the PAR, i.e. mapped to both the $\mathrm{X}$ and $\mathrm{Y}$ chromosomes, or were sex chromosome-specific. Metaphase and interphase chromosome spreads were prepared 
Table 1. Cytogenetically mapped PAR and X-specific genes and markers (in map order)

\begin{tabular}{|c|c|c|c|c|c|c|}
\hline \multirow{2}{*}{$\begin{array}{l}\text { Gene/marker } \\
\text { symbol }\end{array}$} & \multirow{2}{*}{$\begin{array}{l}\text { Type of } \\
\text { sequence }\end{array}$} & \multicolumn{2}{|c|}{ Map location } & \multirow{2}{*}{$\begin{array}{l}\text { Sequence in SSCX } \\
\text { (Sscrofa10.2) }\end{array}$} & \multirow{2}{*}{$\begin{array}{l}\text { Sequence in SSCY; } \\
\text { GenBank accession No. }\end{array}$} & \multirow{2}{*}{$\begin{array}{l}\text { Corresponding } \\
\text { CHORI-247 BACs }\end{array}$} \\
\hline & & FISH & Sscrofa 10.2 & & & \\
\hline CRLF2 & gene & $X p / Y p$ & Un & GL893451.1: 12,561-27,485 & $\mathrm{n} / \mathrm{a}$ & $579 \mathrm{~F} 8,640 \mathrm{H} 13$ \\
\hline CSF2RA & gene & $X p / Y p$ & Un & GL896316.1: 21-12,375 & contig 3607; SAMN01815296 & $579 \mathrm{~F} 8,640 \mathrm{H} 13$ \\
\hline SLC25A6 & gene & $X p / Y p$ & Xqter & $X: 113,743,301-113,746,206$ & $\mathrm{n} / \mathrm{a}$ & $395 \mathrm{M} 18,635 \mathrm{O} 11$ \\
\hline$A R S F$ & gene & $X p / Y p$ & Un & GL894117.1: 2,759-20,486 & contig 5800; SAMN01815296 & $339 \mathrm{~A} 1,640 \mathrm{O} 13$ \\
\hline MXRA5 & gene & $X p / Y p$ & Xqter & $X: 143,912,804-143,940,427$ & contig $3441 ;$ SAMN01815296 & $48 \mathrm{~N} 19,515 \mathrm{M} 22$ \\
\hline PRKXY & gene & $X p / Y p$ & Xqter & $X: 144,130,681-144,164,818$ & contig 8474; SAMN01815296 & $26 \mathrm{~B} 13,108 \mathrm{~N} 16$ \\
\hline SW949a & microsatellite & $X p / Y p$ & Xqter & $X: 144,124,593-144,124,775$ & $\mathrm{n} / \mathrm{a}$ & $26 \mathrm{~B} 13,108 \mathrm{~N} 16$ \\
\hline HDHD1 & gene & $\mathrm{Xp} / \mathrm{Yp}$ & Xpter & $\mathrm{X}: 4,016,053-4,053,447$ & contig 7092; SAMN01815296 & 436011 \\
\hline PNPLA4 & gene & $\mathrm{Xp} / \mathrm{Yp}$ & Xpter & $\mathrm{X}: 4,788,455-4,823,753$ & contig 1004; SAMN01815296 & 435B16 \\
\hline KAL1 & gene & $\mathrm{Xp} / \mathrm{Yp}$ & Xpter & $X: 5,366,015-5,562,572$ & contig 4917; SAMN01815296 & $152 \mathrm{P} 13$ \\
\hline$T B L 1 X$ & gene & $\mathrm{Xp} / \mathrm{Yp}$ & Xpter & $X: 6,423,780-6,538,073$ & $\mathrm{n} / \mathrm{a}$ & $6 \mathrm{D} 24,14 \mathrm{P} 3,703 \mathrm{~A} 8,204 \mathrm{D} 23$ \\
\hline GPR143 & gene & $\mathrm{Xp} / \mathrm{Yp}$ & Xpter & $X: 6,541,513-6,575,981$ & $\mathrm{n} / \mathrm{a}$ & $6 \mathrm{D} 24,14 \mathrm{P} 3,703 \mathrm{~A} 8,204 \mathrm{D} 23$ \\
\hline SHROOM2 & gene & $\mathrm{Xp} / \mathrm{Yp}$ & Xpter & $X: 6,595,889-6,801,781$ & contig 00202; SAMN01815296 & $82 \mathrm{~K} 13$ \\
\hline CH242-24K2.1 & lncRNA gene & $\mathrm{Xp}$ & Xpter & $X: 6,959,367-6,960,018$ & $\mathrm{n} / \mathrm{a}$ & $94 \mathrm{~N} 3,326 \mathrm{C} 23$ \\
\hline$C H 242-24 K 2.2^{\mathrm{a}}$ & lncRNA gene & $\mathrm{Xp}$ & Xpter & $\mathrm{X}: 7,015,573-7,018,840$ & $\mathrm{n} / \mathrm{a}$ & $94 \mathrm{~N} 3,326 \mathrm{C} 23$ \\
\hline
\end{tabular}

Discrepancies between FISH and sequence maps are in bold italic. Un = unassigned; lncRNA = long non-coding RNA.

${ }^{a}$ Markers found by BES analysis.

from short-term peripheral blood lymphocyte cultures of a male pig according to standard protocols [Raudsepp and Chowdhary, 2008a]. The BACs containing putative PAR genes were labeled with biotin-16-dUTP or digoxigenin-11-dUTP using Biotin- or DIG-Nick Translation Mix (Roche) and hybridized in combinations of 2 or 3 to metaphase and interphase chromosomes as previously described [Raudsepp and Chowdhary, 2008a]. Relative order of closely located PAR genes was determined by interphase FISH using multiple 3-probe combinations and dual color experiments. Images for a minimum of 10 metaphase spreads and 30 interphase cells were captured for each experiment, and analyzed with a Zeiss Axioplan2 fluorescence microscope equipped with Isis V5.2 (MetaSystems $\mathrm{GmbH}$ ) software.

\section{BAC End Sequencing, Chromosome Walking and Sequence} Tagged Site Content Mapping

End sequencing of the BAC clones was carried out using the standard T7 (5'-CGCTAATACGACTCACTAT AGGGAGA-3') and SP6 (5'-CCGTCGACATTTAGGTGACACTATAG- $\left.3^{\prime}\right)$ primers and BigDye terminator chemistry (Applied Biosystems). The BES were quality-trimmed, aligned for possible overlaps using Sequencher V 4.8 software (Gene Codes Corporation), evaluated for the presence of repeats (RepeatMasker; http://www.repeatmasker.org/), and BLAST (Ensembl) analyzed to identify corresponding sequences in the pig genome assembly Sscrofa10.2 (table 2). Non-repetitive BES were used to design primers (see above) for additional BAC screening and for sequence tagged site (STS) content mapping. Chromosome walking was carried out around the putative $\mathrm{PAB}$ using BES primers of clone $82 \mathrm{~K} 13$ which contains the SHROOM2 gene. New overlapping clones were isolated from the library and arranged into a contig (fig. 1) by STS content mapping (reciprocal PCRs with BES primers). STS content mapping was also used to detect possible overlaps between all other BAC clones.

\section{Sequence Analysis of the $P A B$}

Demarcation of the PAB sequence was carried out by aligning SSCX sequences from 1 to $7.5 \mathrm{Mb}$ (Sscrofa10.2), sequence contigs of the flow-sorted Y chromosome (our unpublished data) and all BES developed in this study. Alignments and sequence analyses were done with Sequencher 4.8 software, BLAST (http://blast.ncbi. nlm.nih.gov/Blast.cgi) and RepeatMasker.

\section{Tissues Samples, DNA and RNA Extraction}

Genomic DNA samples from adult male and female pigs and porcine embryos were obtained from peripheral blood or embryonic tissues (see below) using standard protocols [Birren et al., 1997]. For gene expression analysis, 8 adult tissues (brain, heart, kidney, lung, liver, spleen, skeletal muscle, and testis) were collected from necropsies. Embryonic tissues were procured via blunt dissection of uterine horns after separation of the fetus and the placenta. Placenta and whole embryos were collected from three 26-day pregnancies (males), while placenta and a panel of 10 tissues (brain, heart, gonads, kidney, liver, lung, skeletal muscle, spleen, small intestine, and stomach, representing ectoderm, mesoderm, and endoderm) were obtained from three 60 -day-old embryos ( 2 males and 1 female). The 26-day and 60-day time points were selected because pig embryos complete organ differentiation after 75 days [McPherson et al., 2004]. The embryos were sexed by PCR (data not shown) using porcine $S R Y$ primers $\left(5^{\prime}-3^{\prime}\right.$ F: GTGAAGACAACTTTCCAAACG, R: GCCACTCTCTCTACCACTTCC; product size 230 bp). The tissues were stored in RNAlater (Ambion) at $-80^{\circ} \mathrm{C}$ until use. Total RNA from tissues was isolated with RNeasy Mini Kit (Qiagen) following the manufacturer's protocol. The samples were treated with DNaseI (Ambion), quality checked with BioAnalyzer 2100 (Agilent) and quantified with a Nanodrop spectrophotometer.

\section{Ethics Statement}

Procurement of porcine tissues was in accordance to the United States Government Principles for the Utilization and Care of 
Table 2. Summary information for the CHORI-247 BACs that were used for mapping the PAR and PAB

\begin{tabular}{|c|c|c|c|c|c|c|}
\hline BAC ID & Gene content & FISH & BES-SP6: repeats and BLAST & $\begin{array}{l}\text { SP6 GenBank } \\
\text { accession }\end{array}$ & BES-T7: repeats and BLAST & $\begin{array}{l}\text { T7 GenBank } \\
\text { accession }\end{array}$ \\
\hline $6 \mathrm{D} 24$ & GPR143, TBL1X & $\begin{array}{l}\mathrm{Xp} / \mathrm{Yp} \\
\mathrm{PAR}\end{array}$ & pig CH242-144C16 on chromosome X (100\%) & JY172533 & pig CH242-236H7 on chromosome X (100\%) & JY172534 \\
\hline $14 \mathrm{P} 3$ & GPR143, TBL1X & $\begin{array}{l}\mathrm{Xp} / \mathrm{Yp} \\
\mathrm{PAR}\end{array}$ & pig CH242-144C16 on chromosome X (100\%) & JY172535 & $\begin{array}{l}\text { LINE/L1; WTSI_1061-62J14 on chromosome Y } \\
\text { (966, 100\%); pig CH242-236H7 on chromosome } \\
\text { X (100\%) }\end{array}$ & JY172536 \\
\hline $26 \mathrm{~B} 13$ & PRKXY, SW949 & $\begin{array}{l}\mathrm{Xp} / \mathrm{Yp} \\
\mathrm{PAR}\end{array}$ & $\begin{array}{l}\text { pig CH242-62E } 3 \text { on chromosome X }(100 \%) \text {; } \\
\text { pig } \mathrm{CH} 242-266 \mathrm{M} 18 \text { on chromosome X }(94 \%)\end{array}$ & JY172537 & pig CH242-62E3 on chromosome X (100\%) & JY172538 \\
\hline 48 N19 & MXRA5 & $\begin{array}{l}\mathrm{Xp} / \mathrm{Yp} \\
\mathrm{PAR}\end{array}$ & no significant similarity & JY172539 & pig $\mathrm{CH} 242-228 \mathrm{~K} 3$ on chromosome $\mathrm{X}(100 \%)$ & JY172540 \\
\hline $82 \mathrm{~K} 13$ & SHROOM2 & $\begin{array}{l}\mathrm{Xp} / \mathrm{Yp} \\
\mathrm{PAR}\end{array}$ & $\begin{array}{l}\text { SINE/tRNA-Glu; pig CH242-236H7 on chromosome X } \\
(100 \%) ; \text { cattle SHROOM2, 2e-16 }\end{array}$ & JY172541 & $\begin{array}{l}\text { LINE/L1; pig CH242-156O11 on chromosome } \mathrm{X} \\
(100 \%)\end{array}$ & JY172542 \\
\hline $94 \mathrm{~N} 3$ & $\begin{array}{l}\text { PIG CH242-24K2.1, } \\
\text { PIG CH242-24K2.2 }\end{array}$ & $\mathrm{Xp}$ & LINE/L1; pig CH242-24K2 on chromosome X (97\%) & JY172543 & $\begin{array}{l}\text { SINE/tRNA-Glu; pig CH242-156O11 on } \\
\text { chromosome X (99\%) }\end{array}$ & JY172544 \\
\hline $108 \mathrm{~N} 16$ & PRKXY & $\begin{array}{l}\mathrm{Xp} / \mathrm{Yp} \\
\mathrm{PAR}\end{array}$ & $\begin{array}{l}\text { SINE/tRNA-Glu; pig CH242-266M18 on chromosome X } \\
(100 \%) \text {; pig CH242-231E5 on chromosome X }(100 \%)\end{array}$ & JY172545 & SINE/tRNA-Glu; no significant similarity & JY172546 \\
\hline $152 \mathrm{P} 13$ & KAL1 & PAR & $\begin{array}{l}\text { pig CH242-507C8 on chromosome X (99\%), pig KAL1, } \\
6 \mathrm{e}-55\end{array}$ & JY172547 & $\begin{array}{l}\text { LTR/ERV1; pig CH242-507C8 on } \\
\text { chromosome X }(99 \%)\end{array}$ & JY172548 \\
\hline $204 \mathrm{D} 23$ & GPR143, TBL1X & $\begin{array}{l}\mathrm{Xp} / \mathrm{Yp} \\
\mathrm{PAR}\end{array}$ & $\begin{array}{l}\text { LINE/L1; pig WTSI_1061-5C19 on chromosome Y (100\%); } \\
\text { pig CH242-144C16 on chromosome X (100\%) }\end{array}$ & JY172549 & $\begin{array}{l}\text { low complexity, SINE/tRNA-Glu; } \\
\text { pig CH242-236H7 and pig CH242-156O11 on } \\
\text { chromosome X (100\%), cattle SHROOM2, 8e-09 }\end{array}$ & JY172550 \\
\hline $326 \mathrm{C} 23$ & $\begin{array}{l}\text { CH242-24K2.1, } \\
\text { CH242-24K2.2 }\end{array}$ & $\mathrm{Xp}$ & pig CH242-24K2 on chromosome X (96\%) & JY172551 & $\begin{array}{l}\text { SINE/tRNA-Glu, LINE/L1; pig CH242-156O11 } \\
\text { on chromosome X (96\%) }\end{array}$ & JY172552 \\
\hline 339A1 & ARSF & $\begin{array}{l}\mathrm{Xp} / \mathrm{Yp} \\
\mathrm{PAR}\end{array}$ & $\begin{array}{l}\text { SINE/MIR; Homo sapiens } 959-\mathrm{kb} \text { contig between } A M L 1 \\
\text { and CBR1 on chromosome } 21 \mathrm{q} 22,4 \mathrm{e}-38\end{array}$ & JY172553 & $\begin{array}{l}\text { Sus scrofa clone KVL9136 microsatellite } \\
\text { sequence, 2e-54 }\end{array}$ & JY172554 \\
\hline $395 \mathrm{M} 18$ & SLC25A6 & $\begin{array}{l}\mathrm{Xp} / \mathrm{Yp} \\
\mathrm{PAR}\end{array}$ & $\begin{array}{l}\text { SINE/tRNA-Glu, LINE/L1, (CAAA) } 8 \text {; pig CH242-266M18 } \\
\text { on chromosome X ( } 81 \%)\end{array}$ & JY172555 & no significant similarity & JY172556 \\
\hline $435 \mathrm{~B} 16$ & PNPLA4 & $\begin{array}{l}\mathrm{Xp} / \mathrm{Yp} \\
\mathrm{PAR}\end{array}$ & pig $\mathrm{CH} 242-236 \mathrm{E} 18$ on chromosome X $(100 \%)$ & JY172557 & pig $\mathrm{CH} 242-207 \mathrm{C} 4$ on chromosome $\mathrm{X}(100 \%)$ & JY172558 \\
\hline $436 \mathrm{O} 11$ & HDHD1A & $\begin{array}{l}\mathrm{Xp} / \mathrm{Yp} \\
\mathrm{PAR}\end{array}$ & $\begin{array}{l}\text { LTR, SINE/tRNA-Glu; pig E-95J7 on chromosome X } \\
(100 \%)\end{array}$ & JY172559 & $\begin{array}{l}\text { LTR/ERVL-MaLR, SINE/tRNA-Glu; } \\
\text { pig CH242-88J14 on chromosome X (97\%) }\end{array}$ & JY172560 \\
\hline $515 \mathrm{M} 22$ & MXRA5 & $\begin{array}{l}\mathrm{Xp} / \mathrm{Yp} \\
\mathrm{PAR}\end{array}$ & pig CH242-266M18 on chromosome X (100\%) & JY172561 & LINE/L1; no significant similarity & JY172562 \\
\hline $579 \mathrm{~F} 8$ & $C R L F 2, C S F 2 R A$ & $\begin{array}{l}\mathrm{Xp} / \mathrm{Yp} \\
\mathrm{PAR}\end{array}$ & $\begin{array}{l}\text { Sus scrofa mRNA, clone: ITT010044E04, expressed in } \\
\text { intestine, } 6 \mathrm{e}-31\end{array}$ & JY172563 & $\begin{array}{l}\text { SINE/tRNA-Glu, }(\mathrm{CA})_{18} ; \text { no significant } \\
\text { similarity }\end{array}$ & JY172564 \\
\hline 635011 & SLC25A6 & $\begin{array}{l}\mathrm{Xp} / \mathrm{Yp} \\
\mathrm{PAR}\end{array}$ & LINE/L1; no significant similarity & JY172565 & LTR/ERVL-MaLR; no significant similarity & JY172566 \\
\hline $640 \mathrm{H} 13$ & $C R L F 2, C S F 2 R A$ & $\begin{array}{l}\mathrm{Xp} / \mathrm{Yp} \\
\mathrm{PAR}\end{array}$ & LTR/ERVL; no significant similarity & JY172567 & $\begin{array}{l}\text { SINE/tRNA-Glu, LTR/ERV1; Sus scrofa mRNA, } \\
\text { clone: ITT010044E04, expressed in intestine, } \\
\text { 4e-12 }\end{array}$ & JY172568 \\
\hline $640 \mathrm{O} 13$ & $A R S F$ & $\begin{array}{l}\mathrm{Xp} / \mathrm{Yp} \\
\mathrm{PAR}\end{array}$ & pig CH242-215D15 on chromosome 7 (76\%) & JY172569 & $\begin{array}{l}\text { LTR/ERVL; pig CH242-228K3 on } \\
\text { chromosome X }(100 \%)\end{array}$ & JY172570 \\
\hline $703 \mathrm{~A} 8$ & GPR143, TBL1X & $\begin{array}{l}\mathrm{Xp} / \mathrm{Yp} \\
\mathrm{PAR}\end{array}$ & $\begin{array}{l}\text { SINE/tRNA-Glu; pig WTSI_1061-35G12 on chromosome Y } \\
\text { (100\%); pig CH242-144C16 on chromosome X (100\%) }\end{array}$ & JY172571 & $\begin{array}{l}\mathrm{CH} 242-236 \mathrm{H} 7 \text { on chromosome X }(98 \%) \text {; } \\
\text { Sus scrofa mRNA, clone: ADR010054D04, } \\
\text { expressed in adrenal gland, } 0.0\end{array}$ & JY172572 \\
\hline
\end{tabular}

$\mathrm{BES}=\mathrm{BAC}$ end sequence.

Vertebrate Animals Used in Testing, Research and Training and was approved by Animal Use Protocol AUP No. 2008-103 at Texas A\&M University.

Gene Expression Analysis

Primers for reverse transcriptase (RT) and quantitative RTPCR (qRT-PCR) were designed from exonic sequences of 15 genes: 9 from the PAR and 6 from X-specific regions (online suppl. ta- ble 3). Expression profiles of 8 genes (5 PAR and $3 \mathrm{X}$-specific) were analyzed by RT-PCR in a panel of adult porcine tissues. RT-PCR reactions were carried out in $15 \mu$ l volume using Superscript III One-Step RT-PCR System and Platinum TaqDNA polymerase (Invitrogen) as previously described [Das et al., 2010; Paria et al., 2011]. Genomic controls were analyzed simultaneously with the RNA samples and housekeeping genes $A C T B$ and GAPDH were used as internal controls. Next, expression levels of all 15 genes 
Fig. 1. Gene map of the pig PAR and Xp. A Sequence map of SSCXp from Sscrofa10.2 draft assembly (Ensembl); arrows with numbers indicate gaps in the current assembly. B FISH map of the pig PAR and adjacent X-specific region. C Metaphase and interphase images showing the location or relative order of PAR genes. Note that SCL25A6 (red) and MXRA5 (green) at $\mathrm{Xp} / \mathrm{Yp}$ (far left) are assigned to $\mathrm{Xq}$ in Sscrofa10.2.

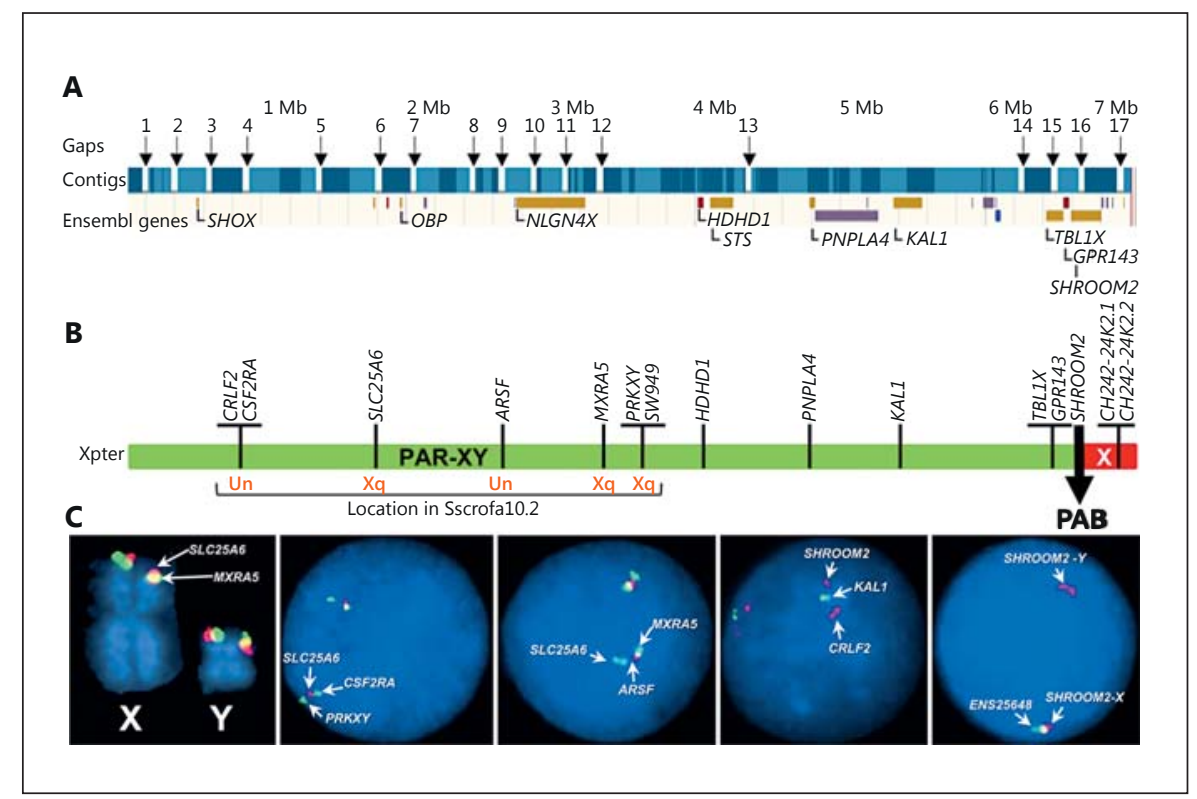

were compared between the 26-day- and 60-day-old placenta and embryos/embryonic tissues by qRT-PCR. The qRT-PCR assays were carried out with SYBR Green PCR kit (Roche) on a LightCycler $^{\circledR} 480$ (Roche Diagnostics) according to the manufacturer's instructions and the results were analyzed with LightCycler 480 Software v1.5. The genes were tested in duplicate reactions in triplicate experiments and the expression of the PAR and X-specific genes was analyzed by absolute quantification method as described elsewhere [Bustin, 2000; Nolan et al., 2006] (Illumina Technical Note: http://www.illumina.com/Documents/products/technotes/technote_eco_absolutequant_sybr_green.pdf). Standard curves for each gene were prepared from cDNA of known template concentrations, such as 200, 100 and $50 \mathrm{ng}$. Gene expression (copies/ $\mu \mathrm{l}$ ) was calculated based on the cDNA concentration ( $\mathrm{ng} / \mu \mathrm{l})$, the lengths of the DNA fragments (bp; e.g. AFF2: 199 bp, KAL1: 194 bp, etc., see online suppl. table 3 ), the number of targets per DNA fragment (copies), the Avogadro constant $\left(\mathrm{NA}=6.0221415 \times 10^{23}\right.$ $\left.\mathrm{mol}^{-1}\right)$, and the average weight of a double-stranded base pair $(650$ $\mathrm{kDa}$ ). The expression of any unknown sample was then determined by interpolation of the PCR signal into this standard curve and presented as the number of transcripts (copies/ $\mu l)$ in test samples.

\section{Results}

\section{A Cytogenetic Map of the Pig PAR}

Twenty BAC clones corresponding to 13 putative pig PAR genes (tables 1,2) were isolated from the CHORI-247 BAC library. BES analysis identified 2 additional markers: a microsatellite SW949 close to PRKXY in clone 26B13 and 2 long non-coding (lnc) RNA genes CH242-24K2.1/2.2 in clones $94 \mathrm{~N} 3$ and 326C23 (tables 1,2). Mapping of the $20 \mathrm{BAC}$ clones to male pig metaphase spreads by FISH assigned 18 clones and 13 genes/markers to the PAR at Xpter/Ypter, and 2 clones with the lncRNA genes to Xpter only, as outlined in figure 1B. Relative order of closely located BACs was determined by interphase FISH (fig. 1C). A linearly ordered cytogenetic map with 15 genes/markers was thus constructed for the porcine PAR and the adjacent $\mathrm{X}$-specific region (fig. 1B, C). Comparison of the FISH map with the pig genome sequence assembly (fig. 1A) showed that the 6 most distal PAR genes, i.e. CRLF2, CSF2RA, SLC25A6, ARSF, MXRA5, PRKXY, and marker SW949, were assigned to contigs Un or to Xqter in Sscrofa10.2 (table 1; fig. 1). However, these genes were unambiguously mapped to Xpter/Ypter by FISH (fig. 1C). Further, alignment of PAR gene sequences, PAR BES, Sscrofa10.2 and sequence contigs of a flow-sorted pig Y chromosome (our unpublished data) showed that 8 PAR genes were present in both the $\mathrm{X}$ and the $\mathrm{Y}$ chromosome (table 1), thus confirming the FISH results. The results also indicated that the $\mathrm{PAB}$ lies within or immediately next to BAC $82 \mathrm{~K} 13$, which contains SHROOM2 and is the most proximal clone that FISH mapped to both sex chromosomes (figs. 1,2).

We infer that the pig has a single PAR which is located terminal in the short arms of the sex chromosomes, has a gene content and order very similar to other mammalian PARs or Xp terminal regions [Raudsepp et al., 2012] and extends approximately up to SHROOM2.

\section{Demarcation of the PAB Sequence}

In order to precisely define the $\mathrm{PAB}$, we constructed a contig of overlapping $\mathrm{BAC}$ clones across the region
30
Cytogenet Genome Res 2013;141:26-36 DOI: $10.1159 / 000351310$
Das/Mishra/Ghosh/Avila/Johnson/ Chowdhary/Raudsepp 
Fig. 2. Demarcation of the porcine $P A B$. Red vertical arrow from $\mathbf{A}$ to $\mathbf{C}$ shows the increasing resolution of the PAB. A BAC contig map spanning the putative $\mathrm{PAB}$ in SSCX. Green and orange rectangles denote STS markers that were used to align the BAC clones. The location of known genes is denoted by green circles. The PAB is narrowed down to a 128,154 -bp region between markers 204D23T7 and 94N3SP6. B Location of the PAB (black circle) in SHROOM2 intron 3-4. C Sequence alignment of PAB-X and PAB-Y in SHROOM2 intron 3-4: $100 \%$ alignment in the PAR (left, green shade) and reduced sequence similarity in sex chromosome-specific regions (right; red and blue shades).

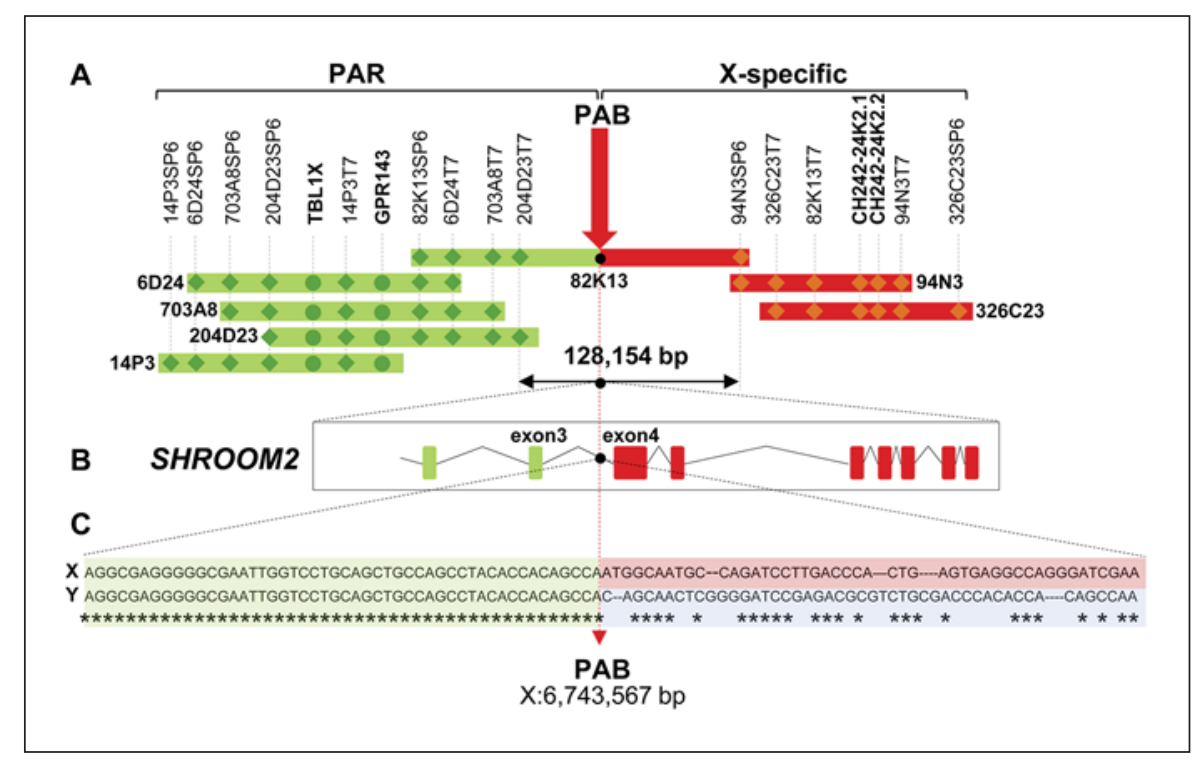

around SHROOM2 (fig. 2A). The contig comprised 7 clones, 4 of which (14P3, 6D24, 703A 8 and 204D23) were located in the PAR and $2(94 \mathrm{~N} 3$ and 326C23) in the Xspecific region. BAC clone $82 \mathrm{~K} 13$ containing the SHROOM2 gene bridged the 2 regions. STS content analysis and BES (table 2) alignments with SSCX sequence assembly (Sscrofa 10.2) narrowed the putative PAB-X down to a 128,154-bp region between BES 204D23T7 and 94N3-SP6 (fig. 2A; online suppl. fig. 1). In Sscrofa10.2 this sequence corresponded to X:6,692,098$6,820,252 \mathrm{bp}$ and contained the proximal part of SHROOM2, from exon 2 onwards (fig. 2B). Because chromosome walking did not identify any $\mathrm{Y}$ chromosome BACs, the sequence of the putative PAB-X was aligned with the sequences of a flow-sorted $\mathrm{Y}$ chromosome (table 1; our unpublished data). We identified Y contig 00202 (828 bp) which showed $97-100 \%$ similarity to a part of SHROOM2 intron 3-4, whereas sequence similarity abruptly dropped to less than $50 \%$ from position $\mathrm{X}: 6,743,567 \mathrm{bp}$ onwards, thus demarcating the porcine PAB (fig. 2C; online suppl. fig. 1). Notably, SINE/ tRNAGlu elements spanned the PAB in both X and Y chromosomes as revealed by RepeatMasker analysis of the $\mathrm{PAB}$ sequences. Alignment of the genomic sequence of SHROOM2 (Ensembl) with the assembled sequences of flow-sorted SSCY (our unpublished data) and with the sequences of SSCY fosmid library WTSI_1061 (NCBI, http:// www.ncbi.nlm.nih.gov/nuccore?term=Pig\%20DNA\%20 sequence $\% 20$ from $\% 20$ clone $\% 20 \mathrm{WTSI}$ ) showed no evidence of the presence of SHROOM2 exons 4-10 in SSCY.
We conclude that the porcine $\mathrm{PAB}$ is located in intron 3-4 of SHROOM2, so that the first 3 exons of the gene are located in the PAR, the remaining exons (4-10) are Xspecific, and the gene is truncated in the $\mathrm{Y}$ chromosome. Based on the sequence position of SHROOM2 in the current $\mathrm{X}$ chromosome sequence assembly, we propose that the porcine PAR is at least $6.7 \mathrm{Mb}$ in size.

\section{Expression Analysis of the Pig PAR and X-Specific \\ Genes}

Demarcation of the PAB not only determined the size and the gene content of the PAR, but also indicated which genes in pigs are functionally diploid on both sex chromosomes, and which undergo $\mathrm{X}$ inactivation in females [Brown and Greally, 2003]. Such discrimination might be important because recent studies in human embryonic and induced pluripotent stem cells show that functional diploidy for the PAR genes might be critical for normal embryonic development [Urbach and Benvenisty, 2009; Li et al., 2012]. That is why we carried out a pilot study profiling the expression of the PAR and X-specific genes in pigs.

As a first step, expression of 5 randomly selected PAR genes and $3 \mathrm{X}$-specific genes was studied by RT-PCR in a panel of 8 adult porcine tissues, i.e. brain, heart, kidney, lung, liver, spleen, skeletal muscle, and testis (online suppl. fig. 2). All genes, regardless of their location, showed nearly ubiquitous expression. Of these, the Xspecific NOX1 had an overall low expression level compared to other genes, and the transcription of PAR genes 


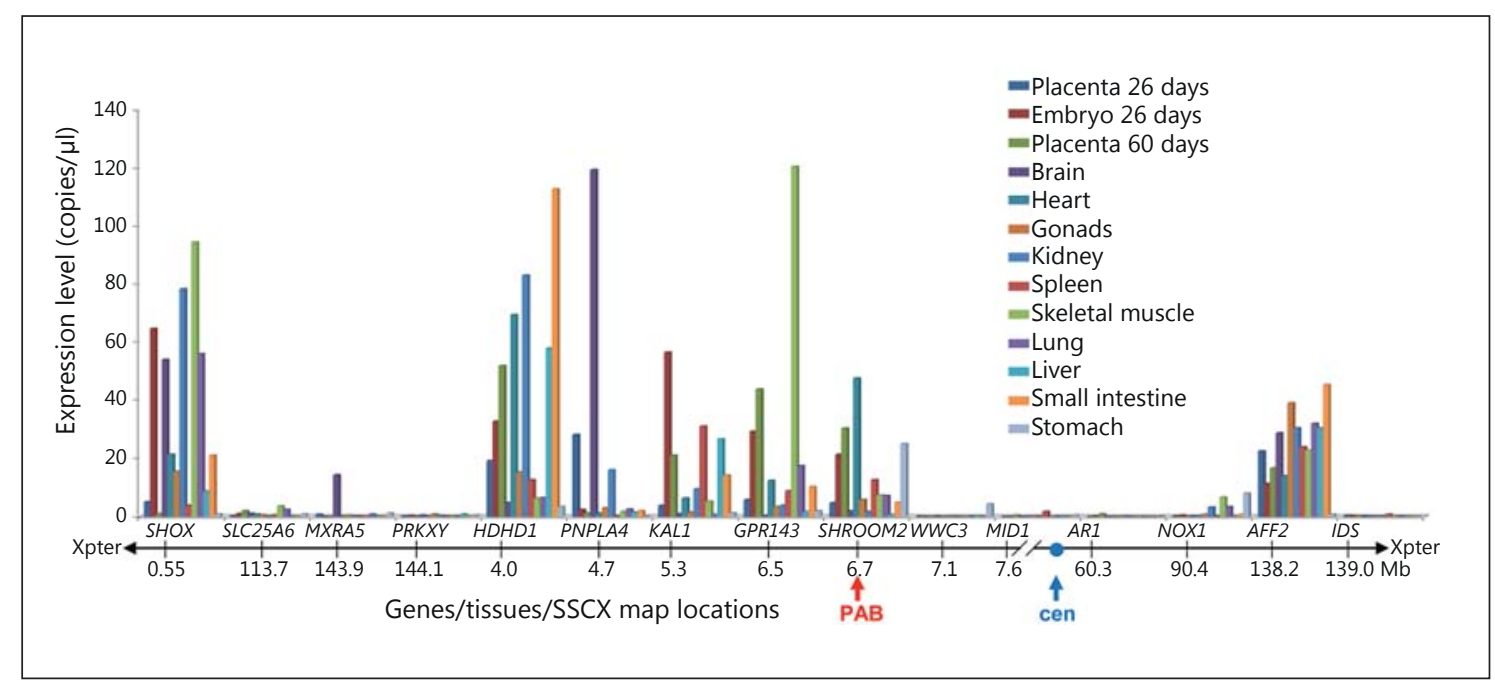

Fig. 3. Expression profiles of selected PAR and X-specific genes in pig embryo and placenta at days 26 and 60 of development. $\mathrm{y}$-axis = expression level; $\mathrm{x}$-axis = linear order of the studied genes in the pig X chromosome and the tissues studied per each gene.

Table 3. Expression of pig PAR (bold italic) and X-specific (italic) genes in early development

\begin{tabular}{|c|c|c|c|c|c|c|c|c|c|c|c|c|c|}
\hline \multirow[t]{2}{*}{ Gene symbol } & \multicolumn{2}{|l|}{26 days } & \multicolumn{11}{|l|}{60 days } \\
\hline & placenta & embryo & placenta & brain & heart & gonads & kidney & spleen & $\begin{array}{l}\text { skeletal } \\
\text { muscle }\end{array}$ & lung & liver & $\begin{array}{l}\text { small } \\
\text { intestine }\end{array}$ & stomach \\
\hline SHOX & 5.09 & 64.67 & 1.02 & 54.00 & 21.46 & 15.54 & 78.34 & 3.91 & 94.35 & 55.97 & 8.81 & 21.11 & 0.90 \\
\hline SLC25A6 & 0.26 & 1.05 & 2.04 & 1.15 & 0.89 & 0.61 & 0.12 & 0.60 & 3.67 & 2.52 & 0.04 & 0.18 & 0.88 \\
\hline MXRA5 & 0.84 & 0.01 & 0.02 & 14.39 & 0.12 & 0.54 & 0.39 & 0.16 & 0.19 & 0.88 & 0.28 & 0.20 & 1.20 \\
\hline PRKXY & 0.28 & 0.42 & 0.05 & 0.50 & 0.19 & 0.86 & 0.41 & 0.25 & 0.15 & 0.22 & 0.86 & 0.29 & 0.56 \\
\hline HDHD1 & 19.23 & 32.81 & 51.89 & 4.86 & 69.43 & 15.32 & 83.00 & 12.66 & 6.34 & 6.57 & 57.98 & 112.60 & 3.44 \\
\hline PNPLA4 & 28.21 & 2.37 & 1.28 & 119.29 & 1.19 & 3.01 & 16.06 & 0.17 & 1.71 & 2.61 & 1.61 & 2.02 & 0.20 \\
\hline$K A L 1$ & 3.85 & 56.55 & 21.13 & 1.07 & 6.39 & 1.54 & 9.61 & 31.12 & 5.26 & 0.78 & 26.74 & 14.28 & 1.27 \\
\hline GPR143 & 5.87 & 29.34 & 43.81 & 0.47 & 12.41 & 3.50 & 3.89 & 8.90 & 120.40 & 17.47 & 1.75 & 10.34 & 2.01 \\
\hline SHROOM2 & 4.82 & 21.43 & 30.38 & 1.92 & 47.61 & 5.85 & 1.80 & 12.76 & 7.41 & 7.25 & 0.74 & 4.91 & 25.05 \\
\hline WWC3 & 0.04 & 0.02 & 0.02 & 0.03 & 0.01 & 0.06 & 0.04 & 0.01 & 0.05 & 0.03 & 0.48 & 0.06 & 4.39 \\
\hline$M 1 D 1$ & 0.01 & 0.02 & 0.49 & 0.01 & 0.05 & 0.13 & 0.04 & 1.77 & 0.01 & 0.04 & 0.14 & 0.10 & 0.57 \\
\hline$A R 1$ & 0.01 & 0.25 & 0.94 & 0.00 & 0.02 & 0.00 & 0.03 & 0.00 & 0.00 & 0.00 & 0.00 & 0.00 & 0.10 \\
\hline NOX1 & 0.29 & 0.55 & 0.05 & 0.24 & 0.34 & 0.85 & 3.32 & 0.13 & 6.73 & 3.43 & 0.16 & 0.74 & 8.10 \\
\hline AFF2 & 22.58 & 11.36 & 16.75 & 28.80 & 14.09 & 39.12 & 30.51 & 24.00 & 22.86 & 32.03 & 30.51 & 45.35 & 0.82 \\
\hline IDS & 0.49 & 0.42 & 0.42 & 0.18 & 0.21 & 0.22 & 0.37 & 0.82 & 0.25 & 0.30 & 0.14 & 0.18 & 0.27 \\
\hline
\end{tabular}

Absolute expression (copies/ $\mu$ l) of each gene across the tissue panel is categorized as: very high $>100$ (red); high $>50-100$ (yellow); medium $>5-50$ (green); low 1-5 (blue), and very low or absent $<1$ (blank).

KAL1 and MXRA5 was prominent in the brain. Because the expression of PAR and non-PAR genes was similar, no qRT-PCR experiments were conducted in adult tissues.

Next, the expression of 15 genes ( 9 from the PAR and 6 from the X-specific region; table 3; fig. 3) was quantified by qRT-PCR in embryonic tissues and the placenta. Absolute expression was calculated for the placenta and whole embryo from day 26, and for the placenta and embryonic heart, liver, lung, skeletal muscle, brain, spleen, kidney, gonads, small intestine, and stomach from day 60 (table 3 ). While the selected PAR genes were confined to the terminal end of SSCXp, the $6 \mathrm{X}$-specific genes were distributed all over the X chromosome - from next to the $\mathrm{PAB}$ (WWC3) 
up to the distal end of the long arm (AFF2 and IDS), as indicated by their approximate $\mathrm{Mb}$ position in the sequence map (fig. 3, online suppl. table 3). Despite this, there was a clear difference in the expression of the 2 groups of genes: 6 out of 9 PAR genes (70\%) showed high- to medium-level expression both in the embryo and placenta, while the expression of non-PAR genes in most embryonic tissues and placenta was very low or absent (fig. 3; table 3). Among the X-specific genes only AFF2 (alias FMR2) showed consistent medium-level expression, while transcripts of 3 PAR genes, viz., SLC25A6, MXRA5 and PRKXY, were absent in almost all tissues (table 3; fig. 3).

Overall, the absolute expression of PAR genes was higher in 60-day-old embryonic tissues and placenta compared to embryos and placenta at 26 days of development. The only exceptions were SHOX and KAL1 that were highly expressed ( $>50-100$ copies/ $\mu$ l) also in the 26-day-old embryos. While the expression of KAL1 reduced to medium or low at day 60, SHOX retained high expression levels in 60-day-old brain, kidney, skeletal muscle and lung (table 3; fig. 3). At both time points, the expression of PAR genes was higher in embryos/embryonic tissues compared to placenta. We did not observe gender differences in the expression of the PAR or Xspecific genes, which was expected because, by definition, PAR genes are functionally diploid in both sexes and the X-inactivation mechanism should equal the expression of $\mathrm{X}$-specific genes between mammalian males and females [Brown and Greally, 2003; Blaschke and Rappold, 2006].

In summary, we observed higher expression of most of the PAR genes compared to the X-specific genes at early stages of embryonic development in pigs, whereas the expression of PAR genes was higher at day 60 compared to day 26 , and higher in embryonic tissues compared to placenta.

\section{Discussion}

The Pig PAR and the Current Pig Genome Sequence Assembly

The study represents an important addition and improvement to the current sequence assembly of the porcine $\mathrm{X}$ chromosome. By constructing a medium-density cytogenetic map for the pig PAR, we unambiguously showed that the sequences of CRLF2, CSF $2 R A$, SLC25A6, ARSF, MXRA5, PRKX, and SW949 truly belong to $\mathrm{Xp}$ and not to $\mathrm{Xq}$ or ChrUn as they are in Sscrofa10.2 (fig. 1). Cytogenetic mapping of these and

The Pig Pseudoautosomal Region and Its Boundary other PAR genes to the terminal ends of Xp and Yp (fig. 1) also confirmed and expanded earlier map data [Quilter et al., 2002]. Most importantly, the discovery of the PAB sequence in SHROOM2 intron 3-4 clearly defined the physical boundaries of the PAR in both sex chromosomes (fig. 2).

The proposed 6.7-Mb size of the porcine PAR as defined in this study, however, is a rough estimate and may increase with the completion of the sequence assembly. For example, the sequence map of the terminal $7 \mathrm{Mb}$ of SSCXp contains 17 gaps (fig. 1), some of which are likely due to the incorrect assignment of PAR sequences to Xq. FISH mapping of genes from CRLF2 to PRKXY and building a BAC contig over the PAB facilitate filling gaps 3-9 and 14-17, respectively (fig. 1). Because of the gaps in the SSCX sequence assembly, the actual size of the porcine PAR might be about $9 \mathrm{Mb}$ which is in accordance with the genomic location of SHROOM2 at $9.7 \mathrm{Mb}$ in the human $\mathrm{X}$ chromosome [Ross et al., 2005].

Difficulties to assemble the PAR have also been observed in other species, including those with finished sequence assemblies like humans, where only $80 \%$ of PAR 1 sequence is available to date [Ross et al., 2005] or mice, where the small $700-\mathrm{kb}$ PAR is still not completely sequenced [Alföldi, 2008]. This is attributed to the specific properties of the PAR sequences, such as increased number of segmental duplications and elevated rate of interspecific sequence polymorphism [Meroni et al., 1996; Ross et al., 2005]. The latter might have affected PAR sequence assembly in pigs more than in other species because the pig genome has been sequenced by a hybrid approach of whole genome shotgun and BAC sequencing, whereas BACs originated from more than one library and individual [Archibald et al., 2010; Swine Genome Sequencing Consortium, 2012].

\section{Comparison of the Pig and Other Eutherian PARs}

Demarcation of the porcine PAB in SHROOM2 at $\mathrm{X}: 6,743,567$ bp includes pig among the mammalian species where the sequence of the PAB has been determined and the PAR is precisely delineated. These include human/primates [Skaletsky et al., 2003; Ross et al., 2005; Hughes et al., 2010, 2012], mouse [Palmer et al., 1997; Perry et al., 2001] and cattle/ruminants [Van Laere et al., 2008]. Though the genomic locations of these PABs are different, they share some striking similarities: all contain SINE elements (tRNAGlu in pigs; Alu in human/chimp, and Bov-tA1/A2 in cattle) and truncate a gene on the $\mathrm{Y}$ chromosome (SHROOM2 in pigs; GPR143 in cattle/ruminants; $X G$ in human/primates, and Mid1 in mouse) 
(fig. 4). These hallmarks of the PAB across evolutionarily diverged species suggest that retrotransposition into a gene is a common and effective evolutionary mechanism to establish a recombination barrier between the sex chromosomes.

In addition to the species with sequenced $\mathrm{PAB}$, approximate location of the boundary and the size of the PAR are known for 6 more mammals, i.e. horse [Raudsepp and Chowdhary, 2008b], porpoise [Van Laere et al., 2008], cat [Murphy et al., 2007], dog [Young et al., 2008], alpaca [Raudsepp et al., 2012], and armadillos [Sciurano et al., 2012]. It appears that eutherian PARs are more alike than previously thought [Das et al., 2009], and the size of the pig PAR is similar, yet not identical, to the PARs of other cetartiodactyls, as well as carnivores (fig. 4). Recent immunocytogenetic studies of meiosis in armadillos indicate that species of Xenartha, one of the basal eutherian orders [Meredith et al., 2011], might have the largest known PAR (8.4-13.6 Mb; fig. 4) among mammals, providing the first 'live' evidence to the theory that the ancestral eutherian PAR extended proximally up to AMELX or further on the X chromosome [Iwase et al., 2003; Park et al., 2005]. Thus, the first and the best studied PARs of human [Ross et al., 2005] and mouse [Ellison et al., 1996], and the PAR of the horse [Raudsepp and Chowdhary, 2008b] are different from other species (fig. 4). Despite this, the map information for the PAR and the adjacent $\mathrm{X}$-specific region in all species studied so far, except mouse, provide compelling evidence about the overall evolutionary conservation and collinearity of this region in eutherian mammals [reviewed by Raudsepp et al., 2012]. Though minor differences exist, like the presence of the odorant binding protein $(O B P)$ gene in the PAR of pigs (fig. 1), cattle and dogs (NCBI; http:// www.ncbi.nlm.nih.gov/sites/entrez?db=gene), but not in other species.

\section{Functional Profiles of Pig PAR Genes in Adult and Embryonic Tissues}

Even though eutherian X chromosomes are largely collinear, different location of the PAB implies that the gene content of eutherian PARs varies (fig. 4), so that a different set of genes undergo or escape $\mathrm{X}$ inactivation and are functionally haploid or diploid, respectively, in different species. Current information about the spatiotemporal expression, molecular functions and genotypephenotype correlations of PAR genes is limited mainly to SHOX and a few other PAR1 loci in humans [Mangs and Morris, 2007; Flaquer et al., 2008]. Because the PAR and $\mathrm{PAB}$ in other eutherians have been demarcated only re-

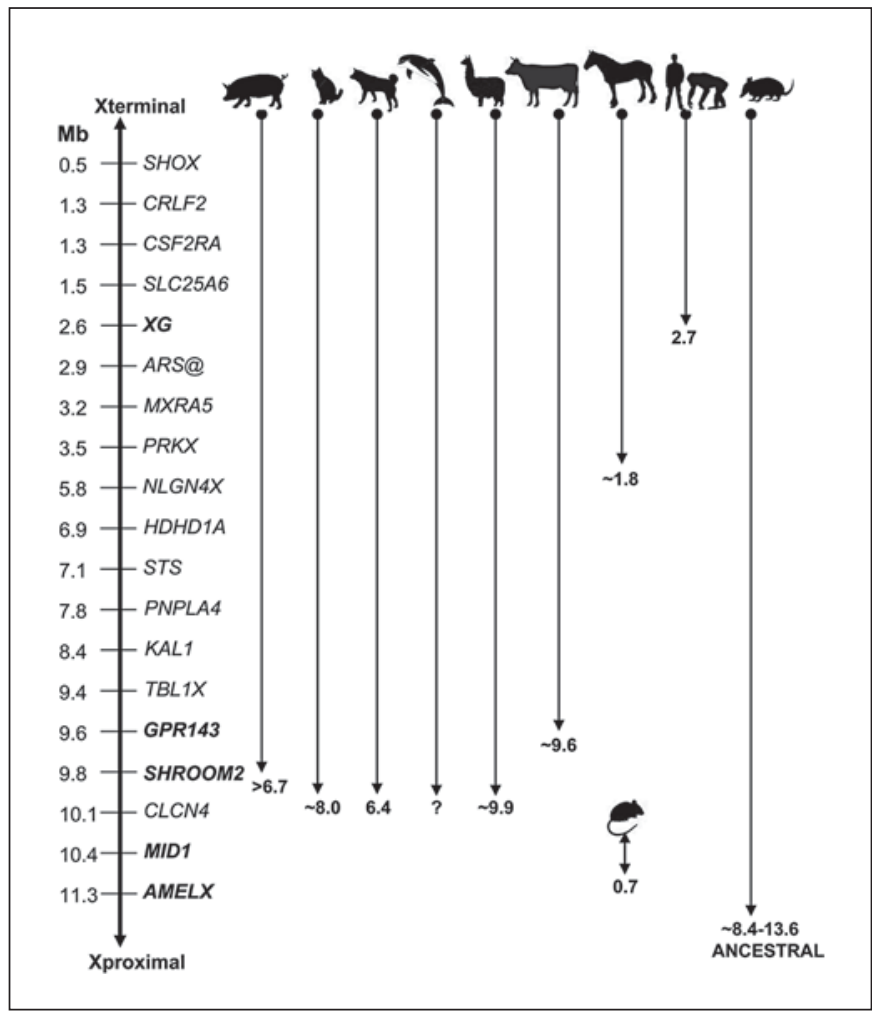

Fig. 4. Comparative status of the gene content and size of the pig and other eutherian PARs. The human Xp sequence map at the left includes only the genes from Sscrofa10.2 that were mapped in this study. The genes at known eutherian PABs are shown in bold.

cently, knowledge about the functional profiles of PAR genes in these species is sparse. The preliminary expression profiles of the PAR and X-specific genes in porcine adult and embryonic tissues, as presented in this study, are thus among the first attempts to improve this knowledge in domestic animals.

Our pilot findings indicate elevated expression of the $\mathrm{PAR}$ genes compared to X-specific genes in porcine embryos (fig. 3; table 3), suggesting that the PAR genes might be important in early development. Initial evidence for this was provided by the studies of human XX and XO embryonic stem cells showing that XO cells which are haploinsufficient for the PAR and other genes that escape $\mathrm{X}$ inactivation, are differentially expressed in placenta [Urbach and Benvenisty, 2009]. Very recently, another human study used induced pluripotent stem cells (iPSCs) from XO individuals to model abnormal early development [Li et al., 2012] and showed that cell lines derived from XO iPSCs display lower expression level of PAR genes than normal controls. Indirectly, 
these findings are supported by the observations that viable XO individuals can be found in species with small PARs (human, horse, mouse) but are rare or absent in species with large PARs (pig, cattle, dog, cat) [Raudsepp et al., 2012], as if haploinsufficiency for too many PAR genes causes embryonic lethality. However, in contrast to the notion of Urbach and Benvenisty [2009] that PAR genes might be necessary for placenta differentiation, the results of this study did not show higher expression of PAR genes in placenta compared to embryos or embryonic tissues (fig. 3; table 3). It is possible that there are differences in developmental gene regulation between species, such as human and pig. Within the limited scope of our study involving $9 \mathrm{PAR}$ and $6 \mathrm{X}$-specific genes, it is also likely that the full spectrum of PAR gene expression was not documented.

Finally, it must be noted that the selection of genes for expression analysis was solely based on their PAR or nonPAR status, and not on their functions. This is probably why very low expression was detected for the X-specific NADPH oxidase 1 (NOX1) in adult tissues (online suppl. fig. 2): the gene is known to be expressed mainly in adult colon [Szanto et al., 2005] and this tissue was not included in the panel. More intriguing was the almost complete absence of the expression of the porcine PAR-linked protein kinase (PRKXY) in embryonic but not in adult tissues (table 3, online suppl. fig. 2). The X-specific ortholog of the gene is known to be expressed in human and murine embryonic and adult tissues, and the gene is considered important for morphogenesis and cellular differentiation
[Li et al., 2005; Li et al., 2009]. Whether the low expression of $P R K X Y$ in pig development is related to its PAR status or other factors needs future studies.

\section{Summary}

This is the first detailed structural and comparative analysis of the porcine PAR and the first pilot study of the expression of PAR genes in domestic species. While the findings improve our overall knowledge about the organization of this region across mammals, and give a hint about the possible role of PAR genes in development, many aspects of the mammalian PAR remain enigmatic. For example, how does the PAR or non-PAR status affect the function of orthologous genes in different species? Complete sequencing and comprehensive functional analysis of the region in species with very large and very small PARs is needed to further unveil the roles of the PAR in mammalian biology.

\section{Acknowledgements}

The study was supported by CVM Postdoctoral award at Texas A\&M University and USDA grant 2006-04801. The authors thank Prof. M.A. Ferguson-Smith at Cambridge Resource Centre for Comparative Genomics (UK) for kindly providing flow-sorted porcine Y chromosomes and Prof. Fuller Bazer at Texas A\&M University for his unfailing support and critical help in the procurement of porcine embryonic and adult tissues.

\section{References}

Alföldi JE: Sequence of the Mouse Y Chromosome, Ph.D. Thesis, Massachusetts Institute of Technology (2008).

-Archibald AL, Bolund L, Churcher C, Fredholm M, Groenen MA, et al: Pig genome sequenceanalysis and publication strategy. BMC Genomics 11:438 (2010).

-Avila F, Das PJ, Kutzler M, Owens E, Perelman P, et al: Development and application of camelid molecular cytogenetic tools. J Hered, Epub ahead of print (2012).

Birren B, Green ED, Klapholz S, Myers RM, Roskams J: Genome Analysis. Analyzing DNA. Laboratory Manual (Cold Spring Harbor Laboratory Press, New York 1997).

Blaschke RJ, Rappold G: The pseudoautosomal regions, SHOX and disease. Curr Opin Genet Dev 16:233-239 (2006).

Brown CJ, Greally JM: A stain upon the silence: genes escaping $\mathrm{X}$ inactivation. Trends Genet 19:432-438 (2003).
Bustin SA: Absolute quantification of mRNA using real-time reverse transcription polymerase chain reaction assays. J Mol Endocrinol 25:169-193 (2000).

Das PJ, Chowdhary BP, Raudsepp T: Characterization of the bovine pseudoautosomal region and comparison with sheep, goat, and other mammalian pseudoautosomal regions. Cytogenet Genome Res 126:139-147 (2009).

Das PJ, Paria N, Gustafson-Seabury A, Vishnoi $\mathrm{M}$, Chaki SP, et al: Total RNA isolation from stallion sperm and testis biopsies. Theriogenology 74:1099-1106, 1106e1-2 (2010).

Duthie CA, Simm G, Perez-Enciso M, DoeschlWilson A, Kalm E, et al: Genomic scan for quantitative trait loci of chemical and physical body composition and deposition on pig chromosome $\mathrm{X}$ including the pseudoautosomal region of males. Genet Sel Evol 41:27 (2009).
Ellegren H, Chowdhary BP, Johansson M, Marklund L, Fredholm M, et al: A primary linkage map of the porcine genome reveals a low rate of genetic recombination. Genetics 137:1089-1100 (1994).

Ellis N, Goodfellow PN: The mammalian pseudoautosomal region. Trends Genet 5:406-410 (1989).

Ellison JW, Li X, Francke U, Shapiro LJ: Rapid evolution of human pseudoautosomal genes and their mouse homologs. Mamm Genome

7:25-30 (1996).
Filatov DA: A gradient of silent substitution rate in the human pseudoautosomal region. Mol Biol Evol 21:410-417 (2004).

- Flaquer A, Rappold GA, Wienker TF, Fischer C: The human pseudoautosomal regions: a review for genetic epidemiologists. Eur J Hum Genet 16:771-779 (2008).
The Pig Pseudoautosomal Region and Its Boundary
Cytogenet Genome Res 2013;141:26-36 DOI: $10.1159 / 000351310$ 
Flaquer A, Fischer C, Wienker TF: A new sex-specific genetic map of the human pseudoautosomal regions (PAR1 and PAR2). Hum Hered 68:192-200 (2009).

Galtier N: Recombination, GC-content and the human pseudoautosomal boundary paradox. Trends Genet 20:347-349 (2004).

-Gustafson AL, Tallmadge RL, Ramlachan N, Miller $\mathrm{D}$, Bird $\mathrm{H}$, et al: An ordered BAC contig map of the equine major histocompatibility complex. Cytogenet Genome Res 102:189195 (2003).

Hughes JF, Skaletsky H, Pyntikova T, Graves TA, van Daalen SK, et al: Chimpanzee and human $\mathrm{Y}$ chromosomes are remarkably divergent in structure and gene content. Nature 463:536539 (2010).

Hughes JF, Skaletsky H, Page DC: Sequencing of rhesus macaque $\mathrm{Y}$ chromosome clarifies origins and evolution of the DAZ (Deleted in AZoospermia) genes. Bioessays 34:10351044 (2012).

Iwase M, Satta Y, Hirai Y, Hirai H, Imai H, et al: The amelogenin loci span an ancient pseudoautosomal boundary in diverse mammalian species. Proc Natl Acad Sci USA 100:52585263 (2003).

Kuzmuk KN, Schook LB: Pigs as a model for biomedical sciences, in Rothschild MF, Ruvinsky A (eds): The Genetics of the Pig, pp 426-444 (CABI, Wallingford 2011).

Li W, Yu ZX, Kotin RM: Profiles of PrKX expression in developmental mouse embryo and human tissues. J Histochem Cytochem 53:10031009 (2005).

Li W, Wang X, Fan W, Zhao P, Chan YC, et al: Modeling abnormal early development with induced pluripotent stem cells from aneuploid syndromes. Hum Mol Genet 21:32-45 (2012).

Li X, Hyink DP, Radbill B, Sudol M, Zhang H, et al: Protein kinase-X interacts with Pin-1 and Polycystin-1 during mouse kidney development. Kidney Int 76:54-62 (2009).

Luedi PP, Dietrich FS, Weidman JR, Bosko JM, Jirtle RL, et al: Computational and experimental identification of novel human imprinted genes. Genome Res 17:1723-1730 (2007).

Mangs A, Morris BJ: The human pseudoautosomal region (PAR): origin, function and $\mathrm{fu}-$ ture. Curr Genomics 8:129-136 (2007).
McPherson RL, Ji F, Wu G, Blanton JR Jr, Kim SW: Growth and compositional changes of fetal tissues in pigs. J Anim Sci 82:2534-2540 (2004).

Meredith RW, Janecka JE, Gatesy J, Ryder OA, Fisher CA, et al: Impacts of the Cretaceous terrestrial revolution and KPg extinction on mammal diversification. Science 334:521524 (2011).

Meroni G, Franco B, Archidiacono N, Messali S, Andolfi G, et al: Characterization of a cluster of sulfatase genes on Xp22.3 suggests gene duplications in an ancestral pseudoautosomal region. Hum Mol Genet 5:423-431 (1996).

-Murphy WJ, Davis B, David VA, Agarwala R, Schaffer AA, et al: A 1.5-Mb-resolution radiation hybrid map of the cat genome and comparative analysis with the canine and human genomes. Genomics 89:189-196 (2007).

Nolan T, Hands RE, Bustin SA: Quantification of mRNA using real-time RT-PCR. Nat Protoc 1:1559-1582 (2006).

Palmer S, Perry J, Kipling D, Ashworth A: A gene spans the pseudoautosomal boundary in mice. Proc Natl Acad Sci USA 94:1203012035 (1997)

- Paria N, Raudsepp T, Pearks Wilkerson AJ, O'Brien PC, Ferguson-Smith MA, et al: A gene catalogue of the euchromatic male-specific region of the horse $\mathrm{Y}$ chromosome: comparison with human and other mammals. PLoS One 6:e21374 (2011).

Park SH, Shin YK, Suh YH, Park WS, Ban YL, et al: Rapid divergency of rodent CD99 orthologs: implications for the evolution of the pseudoautosomal region. Gene 353:177-188 (2005).

Perry J, Palmer S, Gabriel A, Ashworth A: A short pseudoautosomal region in laboratory mice. Genome Res 11:1826-1832 (2001).

Quilter CR, Blott SC, Mileham AJ, Affara NA, Sargent CA, et al: A mapping and evolutionary study of porcine sex chromosome genes. Mamm Genome 13:588-594 (2002).

Raudsepp T, Chowdhary BP: FISH for mapping single copy genes. Methods Mol Biol 422:3149 (2008a).

Raudsepp T, Chowdhary BP: The horse pseudoautosomal region (PAR): characterization and comparison with the human, chimp and mouse PARs. Cytogenet Genome Res 121: 102-109 (2008b).
Raudsepp T, Das PJ, Avila F, Chowdhary BP: The pseudoautosomal region and sex chromosome aneuploidies in domestic species. Sex Dev 6:72-83 (2012)

Ross MT, Grafham DV, Coffey AJ, Scherer S, McLay K, et al: The DNA sequence of the human X chromosome. Nature 434:325-337 (2005).

Rozen S, Skaletsky H: Primer3 on the WWW for general users and for biologist programmers. Methods Mol Biol 132:365-386 (2000).

Sciurano RB, Rahn MI, Rossi L, Luaces JP, Merani MS, et al: Synapsis, recombination, and chromatin remodeling in the XY body of armadillos. Chromosome Res 20:293-302 (2012).

- Sigurdsson MI, Smith AV, Bjornsson HT, Jonsson JJ: HapMap methylation-associated SNPs, markers of germline DNA methylation, positively correlate with regional levels of human meiotic recombination. Genome Res 19:581-589 (2009).

-Skaletsky H, Kuroda-Kawaguchi T, Minx PJ, Cordum HS, Hillier L, et al: The male-specific region of the human $\mathrm{Y}$ chromosome is a mosaic of discrete sequence classes. Nature 423:825837 (2003).

Swine Genome Sequencing Consortium: Analyses of pig genomes provide insight into porcine demography and evolution. Nature 491: 393-398 (2012).

Szanto I, Rubbia-Brandt L, Kiss P, Steger K, Banfi B, et al: Expression of NOX1, a superoxidegenerating NADPH oxidase, in colon cancer and inflammatory bowel disease. J Pathol 207: 164-176 (2005).

Urbach A, Benvenisty N: Studying early lethality of 45,X0 (Turner's syndrome) embryos using human embryonic stem cells. PLoS One 4:e4175 (2009).

Van Laere AS, Coppieters W, Georges M: Characterization of the bovine pseudoautosomal boundary: documenting the evolutionary history of mammalian sex chromosomes. Genome Res 18:1884-1895 (2008).

Young AC, Kirkness EF, Breen M: Tackling the characterization of canine chromosomal breakpoints with an integrated in-situ/in-silico approach: the canine PAR and PAB. Chromosome Res 16:1193-1202 (2008). 